Mongolian Academy of Sciences
Mongolian Journal of Chemistry
Institute of Chemistry \& Chemical Technology

\title{
Fourier Transform Infrared Spectroscopy Study on Cation adsorption on Viscose Rayon Succinate
}

\author{
Khasbaatar Dashkhuu ${ }^{1}$ and Ung Su Choi ${ }^{2}$ \\ ${ }^{1}$ Institute of Chemistry and Chemical Technology, Mongolian Academy of Sciences, \\ Peace avenue 13330, Ulaanbaatar 210351, Mongolia. \\ ${ }^{2}$ Energy Mechanics Research Center, Korea Institute of Science and Technology, Seongbuk gu, \\ Hawolgok dong 39-1,Seoul, Korea.
}

\begin{abstract}
Ion-exchange materials have been considered as suitable material for the recovery of heavy metals in water. A viscose rayon succinate, synthesized from viscose rayon and succinic anhydride in presence of DMSO, to remove trace bivalent metal ions such as $\mathrm{Ag}^{+}, \mathrm{Cu}^{2+}, \mathrm{Ni}^{2+}, \mathrm{Pb}^{2+}$, $\mathrm{Zn}^{2+}$ and $\mathrm{Cr}^{3+}$, was studied using FT-IR for the behavior of metal adsorption. Both esterification and carboxyl bonding of viscose rayon succinate were assigned essentially at 1729 and $1693 \mathrm{~cm}^{-1}$, respectively. And the essential band of bonding between metal and the material was determined at $1625 \mathrm{~cm}^{-1}$. The available adsorption capacity of this fiber was $6.2 \mathrm{mequiv} / \mathrm{g}$. The adsorption of metal ions on the viscose rayon succinate follows the order of $\mathrm{Cu}^{2+}>\mathrm{Cr}^{3+}>\mathrm{Ni}^{2+}>\mathrm{Pb}^{2+}>\mathrm{Zn}^{2+}>\mathrm{Ag}^{+}$with maximum adsorptions capacities $4.2,1.42,0.91,0.83,0.69$ and $0.35 \mathrm{mmol} / \mathrm{g}$, respectively.
\end{abstract}

Keywords: chelating fiber, cellulose, viscose rayon, metal adsorption, carboxyl group, FT-IR, pH selectivity

\section{Introduction}

A $\mathrm{s}$ the high rate of industrial development in the world, contaminants of heavy metals in wastewater originated from industries are increasing as that influence to the balance of our environment as well as human life. Some cancers and serious diseases may be caused from these metals [1-3]. There are lots of methods including chemical precipitation [4], electrolytic methods [5], and adsorption onto activated carbon [6], membrane process [7], and chelating polymer [8] to reduce the heavy metals in wastewater.

More recently, researches have been undertaken to extend to the design of polymeric based ion-exchange fibers for the removal of heavy metals. Several of designs and applications of chelating fibers have received increased attraction and been investigated [8-10]. In particular, scientists have intensified many efforts to modify fibers in such a way that inherent fiber properties are preserved [11]. Whereas, most chelating polymers are composed of petroleum-based synthetic polymers [12-14]. Furthermore, the used synthetic chelating polymers often produce on secondary environmental pollution by contaminating the soil or air. In addition, these are usually nonrenewable and nondegradable [14].

Viscose rayon is regenerated from cellulose which has renewability [15] and biodegradability [16] and there is more cellulose on earth than any other organic substance [17]. Cellulose itself has a very low ion exchange capacity $[18,19]$. The ionexchange properties of cellulose are similar to other ion exchange resins, but cellulose ion exchangers are more finely divided than 
ordinary ion exchange resins, present a larger surface, because of their porous structure, permit the entrance or attachment of larger molecules which are not readily adsorbed by other resins. The rate of exchange is also very rapid in the case of cellulose ion exchangers [19]. One very attractive feature of cellulose is its chemical composition, with a large amount of relatively easily accessible hydroxyl groups that can be used for attachment of a variety of functional groups. Succinic groups can introduce at positions C2, C3, and C6 of each anhydroglucose unit, where available hydroxyl groups exist, in viscose rayon. The vicinal carboxyl groups of succinate are separated by a single bond and are free rotation which allows more flexibility in accommodating the special requirements of larger cations [20].

In this study, carboxylic acid functionalities were introduced to viscose rayon by chemical modification of succinic anhydride in presence of DMSO. The modified viscose rayon was then characterized by Fourier transform infrared, ${ }^{13} \mathrm{C}$ nuclear magnetic resonance spectroscopes and SEM. Adsorption behavior of metal ions such as silver, copper, zinc, nickel, lead and chromium on the synthesized viscose rayon succinate were demonstrated using quantitative analyses and FT-IR under various $\mathrm{pH}$ which is one of the fundamental characteristics of aqueous solutions.

\section{Experimental}

Materials. Viscose rayon felt, succinic anhydride and Dimethylsulfoxide /DMSO/ were used for substrate, reagent and solvent and purchased from /company of viscose rayon/, Dea Jung chemicals \& metals CO., Ltd., Korea, respectively. $\mathrm{Ag}\left(\mathrm{NO}_{3}\right)$, $\mathrm{Cu}\left(\mathrm{NO}_{3}\right)_{2} \cdot x \mathrm{H}_{2} \mathrm{O}, \quad \mathrm{Ni}\left(\mathrm{NO}_{3}\right)_{2} \cdot 6 \mathrm{H}_{2} \mathrm{O}$, $\mathrm{Zn}\left(\mathrm{NO}_{3}\right)_{2} \cdot 6 \mathrm{H}_{2} \mathrm{O}, \mathrm{Pb}\left(\mathrm{NO}_{3}\right)_{2}$ and $\mathrm{CrCl}_{3} \cdot 6 \mathrm{H}_{2} \mathrm{O}$ (Sigma Chemical Co.) were utilized for testing of being absorbed those metal ions on the ion-exchanger and, $1 \mathrm{~N} \mathrm{NaOH}$ and $1 \mathrm{~N}$ $\mathrm{HNO}_{3}$ were supplied from Sigma Chemical Co.

\section{Synthesis of ion-exchange viscose rayon.}

An ion-exchange viscose felt was synthesized from viscose rayon felt (ca. $10 \mathrm{~cm}$ $\mathrm{x} 10 \mathrm{~cm}, 5 \mathrm{~g}$ and $2.8 \mathrm{~mm}$ thick), succinic anhydride $(50 \mathrm{~g})$, and $\mathrm{DMSO}(500 \mathrm{ml})$ for $5 \mathrm{~h}$ at $80^{\circ} \mathrm{C}$ with spin. The synthesized viscose rayon succinate washed by cold and hot distilled water and dried in a freeze drier at $50^{\circ} \mathrm{C}, 5$ Torr , for 24 hours.

Measurements. Fourier transform infrared spectra $\left(4000-200 \mathrm{~cm}^{-1}, \mathrm{KBr}\right.$ disc) were recorded on a GX FTIR, PerkinElmer spectrometer. ${ }^{13} \mathrm{C}$ NMR was taken on Bruker MSL200 spectrometer in the solid state. The polymers were investigated in a scanning electron microscopy (SEM). The $\mathrm{pH}$ values were measured using a pH 300 (Hanna Instruments) digital $\mathrm{pH}$ meter. The quantitative analysis of adsorbed ions was carried out with atomic adsorption spectrophotometry (AAS; SpectraAA 800, Varian).

Quantitative analysis of the adsorption of $\mathrm{Ag}^{+}, \mathrm{Cu}^{2+}, \mathrm{Ni}^{2+}, \mathrm{Pb}^{2+}, \mathrm{Zn}^{2+}$ and $\mathrm{Cr}^{3+}$

$100 \mathrm{ml}$ and $\mathrm{pH}$ adjusted solutions including $10 \mathrm{mM} \mathrm{Ag}^{+}, \mathrm{Cu}^{2+}, \mathrm{Ni}^{2+}, \mathrm{Pb}^{2+}, \mathrm{Zn}^{2+}$ and $\mathrm{Cr}^{3+}$, separately, and $0.1 \mathrm{~g}$ of the viscose rayon succinate were placed in Erlenmeyer flasks and shaken for $24 \mathrm{~h}$ at 200rpm. The concentration of ionic metal not removed from the solution was determined by AAS. The chelating fibers with metal were dried at $40^{\circ} \mathrm{C}$ in a vacuum oven for 24 hours and characterized by FT-IR spectrometer. In this study, the concentrated $\mathrm{HNO}_{3}$ was used to adjust the pHs of metal ion aqueous solutions. In order to obtain an adsorption capacity of the chelating fiber, $0.1 \mathrm{~g}$ of the viscose rayon succinate and $100 \mathrm{ml}$ of $0.1 \mathrm{~N} \mathrm{NaOH}$ solution in an Erlenmeyer flask was shaken for $24 \mathrm{~h}$ at $200 \mathrm{rpm}$, then a $30 \mathrm{ml}$ of solution sampled from the shaken solution was measured using an auto-titrator (Metrohm 728, Swiss) utilizing a $0.1 \mathrm{~N} \mathrm{HCl}$ solution as back titration.

\section{Results and Discussion}

The viscose rayon succinate was successfully synthesized from viscose rayon and succinic anhydride in presence of DMSO (scheme 1). The adsorption capacity of the viscose rayon succinate is $6.2 \mathrm{meq} / \mathrm{g}$.

Figure 1 shows ${ }^{13} \mathrm{C}$ NMR of viscose rayon and the chelating fiber. The application of ${ }^{13} \mathrm{C}$ NMR is more successful than ${ }^{1} \mathrm{H}$ NMR for the study of cellulose and cellulose derivatives [21]. The chemical shifts carbons in viscose 
rayon (A) are obtained as typical chemical shifts of cellulose. Resonances for the internal (b) and (d) carbons in viscose rayon and viscose rayon succinate are observed at 105 and 87.3ppm, and 105 and 88ppm, respectively. Obviously, it is seen that no degradation is occurred in terms of the synthesizing according to that almost no chemical shifts of (b) and (d) carbons of the viscose rayon succinate are significantly observed. In ${ }^{13} \mathrm{C}$ NMR spectra of (B), four chemical shifts $(\mathrm{g}),(\mathrm{h}),(\mathrm{i}),(\mathrm{j})$ of carbons are assigned at 173.8, 176, 39.8, and 29.9ppm, respectively. Those signals can demonstrate succinic groups successfully introduced on viscose rayon, in particularly resonance line for the $(\mathrm{g})$ of the viscose rayon succinate at 173.8ppm [29]. The signals are shown in table 1 .

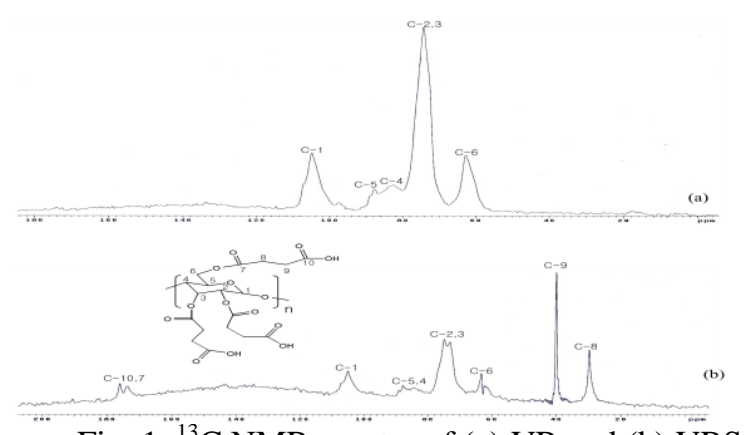

Fig. 1, ${ }^{13}$ C NMR spectra of (a) VR and (b) VRS

Typical SEM image of the viscose rayon which has a diameter of $9 \mu \mathrm{m}$, exhibits a characteristic serrated surface [12] in Fig.2(a). A surface of the viscose rayon succinate is shown in Fig.2(b). A slight difference of the viscose rayon succinate can be observed surface rougher than that of the viscose rayon.

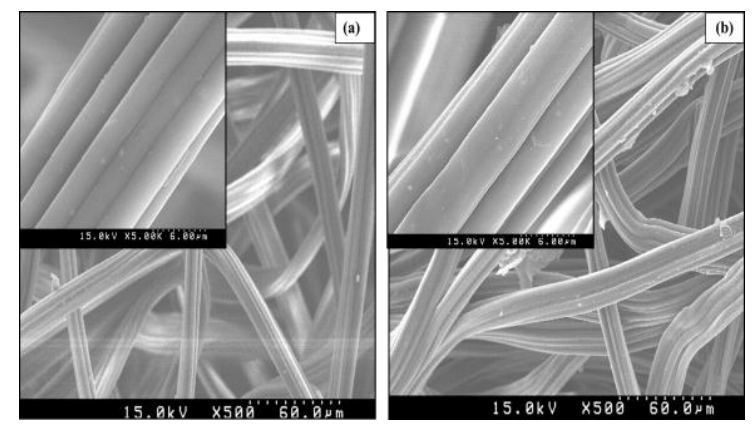

Fig. 2, SEM images of (a) Viscose rayon and (b) Viscose rayon succinate.

FT-IR spectra of viscose rayon felt (a), the viscose rayon succinate (b), the viscose rayon succinate with metal complexes such as $\mathrm{Cu}^{2+}$
$4.2 \mathrm{mmol} / \mathrm{g}$ at $\mathrm{pH} 5(\mathrm{c}), \mathrm{Ni}^{2+} 0.91 \mathrm{mmol} / \mathrm{g}$ at $\mathrm{pH} 6(\mathrm{~d}), \mathrm{Zn}^{2+} 0.69 \mathrm{mmol} / \mathrm{g}$ at $\mathrm{pH} 6.3$ (e), $\mathrm{Pb}^{2+} 0.83 \mathrm{mmol} / \mathrm{g}$ at $\mathrm{pH} 5$ (f), $\mathrm{Ag}^{+} 0.35 \mathrm{mmol} / \mathrm{g}$ at $\mathrm{pH} 8(\mathrm{~g})$, and $\mathrm{Cr}^{3+} 1.42 \mathrm{mmol} / \mathrm{g}$ at $\mathrm{pH} 4(\mathrm{~h})$ are shown in Fig. 3. All of IR spectra exhibit a broad and intense band in the $3000-3700 \mathrm{~cm}^{-}$ 1 region which is assigned to free and hydrogen bonded $\mathrm{OH}$ stretching vibration. In most hydrocarbons, the $\mathrm{CH}_{2}$ asymmetric stretch is near $2930 \mathrm{~cm}^{-1}$. The IR spectra except viscose rayon are characterized by absorption a symmetrical band around 2930 $\mathrm{cm}^{-1}\left(\mathrm{CH}_{2}\right.$ and $\mathrm{CH}$ groups) and this band is switched from absorption peak at $2891 \mathrm{~cm}^{-1}$, which is assigned to symmetric band $\mathrm{CH}$ of viscose rayon. A peak at $1644 \mathrm{~cm}^{-1}$ was assigned to water absorption in viscose rayon. Despite a peak of viscose rayon spectrum is observed at $1160 \mathrm{~cm}^{-1}$, it should be mentioned that the very strong band at $1163 \mathrm{~cm}^{-1}$ is assigned to the $\mathrm{C}-\mathrm{O}$ stretching in the esters $\left(\mathrm{O}(\mathrm{C}=\mathrm{O}) \mathrm{CHCH}_{2}\right)$ of viscose rayon succinate. Carboxylic esters, and carboxylic acids show a strong $\mathrm{C}=\mathrm{O}$ stretching absorption band in the region of $1870-1540 \mathrm{~cm}^{-1}$ [22]. This sharp peak is not observed in spectra of viscose rayon.

New strong peaks of viscose rayon succinate with metal ions such as $\mathrm{Ag}^{+}, \mathrm{Cu}^{2+}$, $\mathrm{Ni}^{2+}, \mathrm{Pb}^{2+}, \mathrm{Zn}^{2+}$ and $\mathrm{Cr}^{3+}$, appeared at a range of $1721-1739 \mathrm{~cm}^{-1}$.

Furthermore, not big intensity peaks were found at $1639 \mathrm{~cm}^{-1}, 1623 \mathrm{~cm}^{-1}, 1641 \mathrm{~cm}^{-1}$, $1546 \mathrm{~cm}^{-1}, 1639 \mathrm{~cm}^{-1}$, and $1737 \mathrm{~cm}^{-1}$ corresponded to ionic bonding formed between $\mathrm{COO}^{-}$with $\mathrm{Ag}^{+}, \mathrm{Cu}^{2+}, \mathrm{Ni}^{2+}, \mathrm{Pb}^{2+}$, $\mathrm{Zn}^{2+}$ and $\mathrm{Cr}^{3+}$, respectively. The bonds between carboxyl groups and metals can influence to the intensity of peak of carboxyl group of the viscose rayon succinate. It is explained that the band of carboxyl groups with metal shifted to low frequency because of this bond to hinder vibration of carboxyl groups. On the other hand, the absorption of the carboxyl group shifted to lower wavelength was attributed to the absorption of carboxyl group with metals according to the formation of the chelating complex which weakens the double bonding property of carbonyl groups owing the coordinate bond between oxygen atoms of carbonyl groups and metal ions [23]. In general, there is a 
correlation between frequency of peak attributed to carboxyl-metal bond and the ionic radii. This result indicates that the ionic radius increases, the frequency decrease [24, 25]. Definitely, the formation of the chelate ring and its resultant geometry has a direct effect on the $\mathrm{COO}^{-}$bond. It is interesting to note that frequency of $\mathrm{Zn}^{2+}$ is higher than $\mathrm{Cu}^{2+}$. The peak assigned at $1639 \mathrm{~cm}^{-1}$ of viscose rayon succinate with $\mathrm{Zn}^{2+}$ corresponds to a syn-syn bridging carboxylate ligand [26].
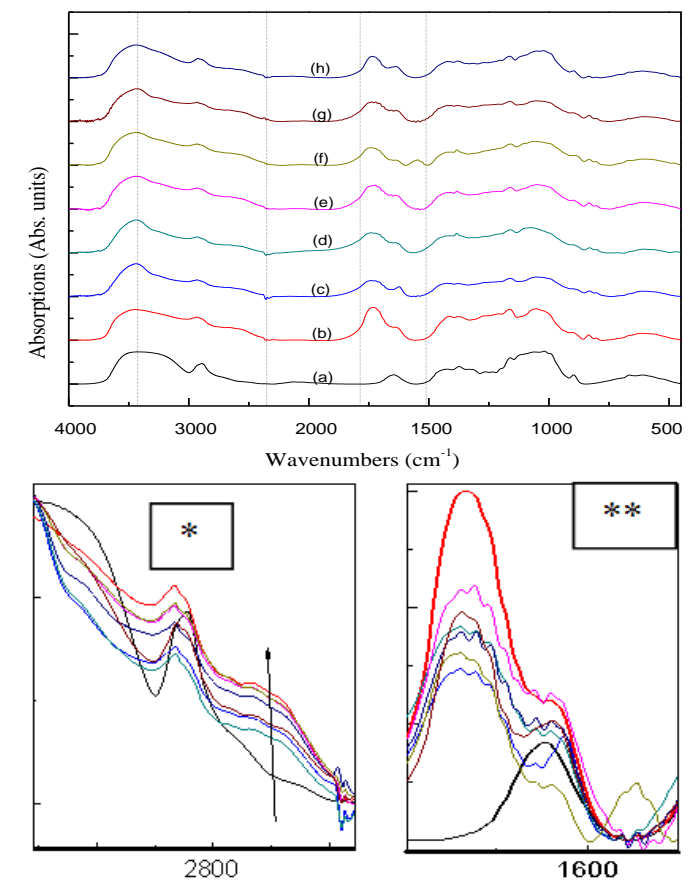

Fig. 3. FT-IR spectroscopy of (a) VR, (b) VRS, VRS with metal ion complexes: (c) $\mathrm{Cu}^{2+} 4.2 \mathrm{mmol} / \mathrm{g}$ at $\mathrm{pH} 5$, (d) $\mathrm{Ni}^{2+}$ $0.91 \mathrm{mmol} / \mathrm{g}$ at $\mathrm{pH} 6$, (e) $\mathrm{Zn}^{2+} 0.69 \mathrm{mmol} / \mathrm{g}$ at $\mathrm{pH} 6.3$, (f) $\mathrm{Pb}^{2+}$ $0.83 \mathrm{mmol} / \mathrm{g}$ at $\mathrm{pH} 5,(\mathrm{~g}) \mathrm{Ag}^{+} 0.35 \mathrm{mmol} / \mathrm{g}$ at $\mathrm{pH} 8$, and (h) $\mathrm{Cr}^{3+} 1.42 \mathrm{mmol} / \mathrm{g}$ at $\mathrm{pH} 4$.

Figure 4 shows quantitative analyses of heavy metals adsorbed on the viscose rayon succinate under increasing $\mathrm{pH}$. The difference between heavy metal ions adsorbed on the viscose rayon succinate attributes with the chemical and physical properties of metal ions and chelating agent in $\mathrm{pH}$ range of 1.0-8. For increasing $\mathrm{pH}$, the behavior of the viscose rayon succinate turns to more reactivity with metals. In acid medium, the viscose rayon succinate is highly protonated and it reduces the attracting effect of the metal ion due to lack of negative charge. The $4.28 \mathrm{mMol}$ of $\mathrm{Cu}^{2+}$ in 1 liter aqueous solution adsorbed on a gram of the viscose rayon succinate at $\mathrm{pH}$ 5.01 is the maximum adsorption. As seen figure 4 , the maximum adsorptions of metal ions can be ordered as $\mathrm{Cu}^{2+}>\mathrm{Cr}^{3+}>\mathrm{Ni}^{2+}$ $>\mathrm{Pb}^{2+}>\mathrm{Zn}^{2+}>\mathrm{Ag}^{+}$. $\mathrm{Cu}^{2+}$ was much more quantity as compared from other metal ions under the same conditions. The values of $\mathrm{K}_{\mathrm{f}}$, defined as the formation rate constants between $\mathrm{COO}^{-}$and Metal ions, increase with the charge of the metal ion. $\mathrm{K}_{\mathrm{f}}$ values of $\mathrm{Ag}^{+}$, $\mathrm{Cu}^{2+}, \mathrm{Ni}^{2+}, \mathrm{Pb}^{2+}, \mathrm{Zn}^{2+}$ and $\mathrm{Cr}^{3+}$, were found to be $1.5 \times 10^{12}, 7.5 \times 10^{9}$, and $3 \times 10^{7}$ for $\mathrm{CH}_{3} \mathrm{COO}^{-}$ , respectively [27]. Moreover, the equilibrium quotients $(\log K)$ represent also the same order as 2.3, 2.01, and 1.08 [28] for $\mathrm{Cu}^{2+}$, $\mathrm{Pb}^{2+}$, and $\mathrm{Zn}^{2+}$, respectively. The adsorptions under the $\mathrm{pH}$ range were also investigated through FT-IR spectroscopy.

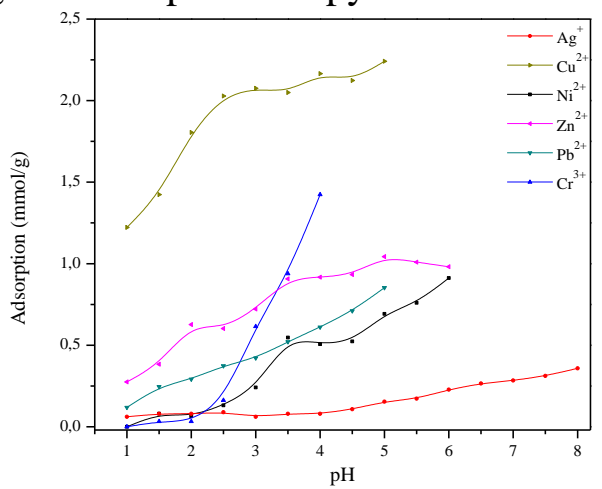

Fig. 4. Effect of $\mathrm{pH}$ on the adsorption of $\mathrm{Ag}^{+}, \mathrm{Cu}^{2+}$, $\mathrm{Ni}^{2+}, \mathrm{Pb}^{2+}, \mathrm{Zn}^{2+}$ and $\mathrm{Cr}^{3+}$

FT-IR spectra of $\mathrm{Cu}^{2+}$, which is on behave of spectra of $\mathrm{Ag}^{+}, \mathrm{Ni}^{2+}, \mathrm{Pb}^{2+}, \mathrm{Zn}^{2+}$ and $\mathrm{Cr}^{3+}$ ions, adsorbed on the viscose rayon succinate with increasing $\mathrm{pH}$ are shown in figure 5 . The intensities observed at $1724 \mathrm{~cm}^{-1}, 3436 \mathrm{~cm}^{-1}$ and attributed to ionic bonded between carboxyl and copper, and hydrogen bonded $\mathrm{OH}$, respectively, decreased with decreasing $\mathrm{pH}$. A reason of the decreased intensity at $3436 \mathrm{~cm}^{-1}(\mathrm{O}-\mathrm{H} . . \mathrm{O})$ is that the number of hydroxide carried by metal ions was decreased due to the reduced amount of metal ions bonded with the chelating fiber. At the same time by decreasing $\mathrm{pH}$, the intensity of the peak assigned at $1736 \mathrm{~cm}^{-1} \quad(\mathrm{C}=\mathrm{O})$ increased as switching from reduced amount of ionic bonds between carboxyl group and copper. The peak observed at $1656 \mathrm{~cm}^{-1}$ assumed to the bond shown in fig.6. (b) due to oxygen of a single carboxyl do not depend each other through the metal ion. Moreover, Fig. 6 (a) they linked through the metal ion. In this case, their vibration is hindered and calculated to lower frequency. 

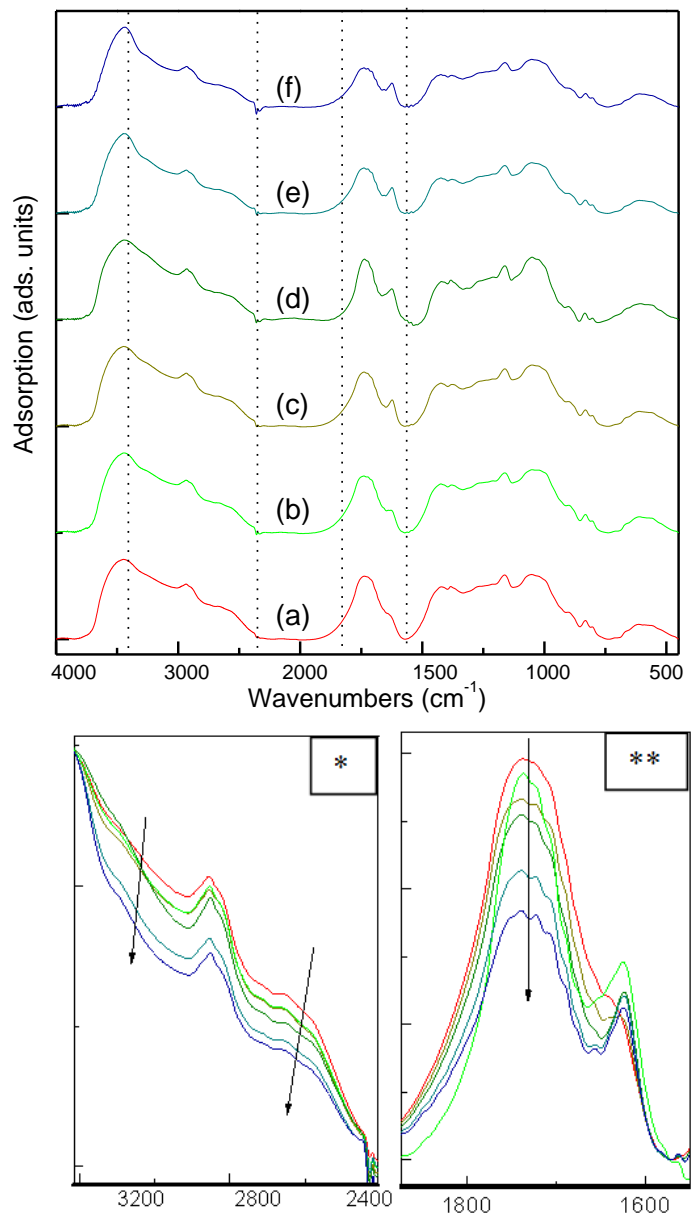

Fig.5. FT-IR spectra of VRS and VRS with $\mathrm{Cu}^{2+}$ increasing $\mathrm{pH}$; (a) $\mathrm{pH} 2.5$; (b) $\mathrm{pH} 3$; (c) $\mathrm{pH} 3.5$; (d) $\mathrm{pH} 4$; (e) $\mathrm{pH} 4.5$; (f) $\mathrm{pH} 5$

\section{Conclusions}

In this study, viscose rayon succinate (chelating fiber) was synthesized from viscose rayon and succinic anhydrate in presence of DMSO. The synthesis was successfully confirmed by ${ }^{13} \mathrm{C}$ NMR and FTIR. Moreover, a new very strong peak appearing at $1733 \mathrm{~cm}^{-1}$ was attributed to $\mathrm{C}=\mathrm{O}$ bonds. The general trends of decreasing frequency with increasing ionic radii, which were observed for the viscose rayon succinate metal ions complexes, were confirmed in the FT-IR spectra. An adsorption capacity of the viscose rayon succinate was $6.2 \mathrm{meq} / \mathrm{g}$. Identical feature for each adsorptions frequency decreasing with decreasing $\mathrm{pH}$ were observed. The maximum metal ions adsorbed can be classified as $\mathrm{Cu}^{2+}>\mathrm{Cr}^{3+}>\mathrm{Ni}^{2+}$ $>\mathrm{Pb}^{2+}>\mathrm{Zn}^{2+}>\mathrm{Ag}^{+}$and such as $4.2 \mathrm{mmol} / \mathrm{g}$, $1.42 \mathrm{mmol} / \mathrm{g}, \quad 0.91 \mathrm{mmol} / \mathrm{g}, \quad 0.83 \mathrm{mmol} / \mathrm{g}$, $0.69 \mathrm{mmol} / \mathrm{g}, 0.35 \mathrm{mmol} / \mathrm{g}$, and respectively. Amount of adsorption $\mathrm{Cu}^{2+}$ on viscose rayon succinate is much higher than other metal ions under the same conditions.

\section{Acknowledgement}

The authors would like to acknowledge the financial support from Korea Institute of Science and Technology.

\section{References}

1. Kaiser, J. (2002) Science 296, 452.

2. DiDonato, M., Hsu, H.F., Narindrasorasak, S., Que, L. Jr., Sarkar, B. (2000) Biochemistry 39, 1890.

3. Stadtman, E. R., Berlett, B. S. (1997) Chem. Res. Toxicol., 10, 485.

4. Matlock, M. M., Howerton B. S., Atwood, D. A. (2002) Water Research 36, 4757.

5. Yang, Ch. Ch. (2003) Journal of Power Sources 115, 352.

6. Chen, J. P., Wu, S. N. (2004) Langmuir 20, 2233.

7. Ueberfeld, J., Parthasarathy, N., Zbinden, H., Gisin, N., Buffle, J. (2002) Anal. Chem. 74, 664.

8. Ko, Y. G., Choi, U. S., Kim, T. Y., Ahn, D. J., Chun, Y. J. (2002) Macromolecular Rapid Communications 23, 535.

9. Gong, B. (2002) Talanta 57, 89.

10. Liu, C., Huang, Y., Naismith, N., Economy, J. Talbott, J. (2003) Environ. Sci. Technol. 37, 4261.

11. Gellerstedt, F., Gatenholm, P. (1999) Cellulose 6, 103.

12. Egawa, H., Nonaka, T., Abe, S., Nakayama, M. (1992) Journal of Applied Polymer Science 45, 837.

13. Liu, C. Y., Chen, M. J., Lee, N. M., Hwang, H. C., Jou S. T., Hsu, J. C. (1992) Polyhedron 11, 551.

14. Kweon, D. K., Choi, J. K., Kim, E. K., Lim, S. T. (2001) Carbohydrate Polymers 46, 171.

15. Richardson, S., Gorton, L. (2003) Analytica Chimica Acta 497, 27.

16. Gross, R. A., Kalra, B. (2002) Science 297, 803.

17. Jarvis, M. (2003) Nature 426, 611.

18. Wegscheider, W., Knapp, G. (1981) $C R C$ Crit. Rev. Anal. Chem. 11, 79.

19. Sahni, S. K., Reedijk, J. (1984) Coordination chemistry reviews $\mathbf{5 9}, 1$. 
20. Lehrfeld, J. (1996) J. Appl. Polym. Sci. 61, 2099.

21. Nehls, I., Wagenhnecht, W., Philipp B., Stscherbina, D. (1994) Prog. Polym. Sci. 19, 29.

22. Colthup, N. B., Daly, L. H. (1964) Introduction to Infrared and Raman Spectroscopy, Academic press inc: London.

23. Maekawa, E., Koshijima, T. (1990) Journal of Applied Polymer Science 40, 1601.

24. Wang, Ch. Ch., Chang, Ch. Y., Chen, Ch. Y. (2001) Macromolecular Chemistry and Physics 202, 882.
25. Sawyer, D. T., Paulsen, P. J. (1958) J. Am. Chem. Soc. 81, 816.

26. William Clegg, Dale R. Harbron, Christopher D. Homan, Paul A. Hunt, Ian R. Little and Brian P. S, (1991) Inorg. Chim. Acta. 186, 51.

27. Martell, A. E. (1978) Coordination Chemistry Volume 2, ACS Monograph 174.

28. Martell, A. E., Smith (1977) R. M. Critical Stability Constants, Volume 3: Other Organic Ligands.

29. Anita J. Brandolini, Deborah D. Hills (2000) NMR Spectra of Polymers and Polymer Additives. 